\title{
Housing Price and Macroeconomic Research Review
}

\author{
Yuwei Ma \\ International Business School \\ Shaanxi Normal University \\ Xi'an, Shaanxi, China \\ 15291072421@163.com
}

\begin{abstract}
In order to understand the current research methods and theoretical progress of housing price and macroeconomics, the existing literature was comparatively analyzed through literature review. It is found that housing prices and macroeconomic problems are attracting more and more attention from scholars. The influence factors of house price and macro economy are the hot spots in the study of house price and macro economy in recent years.
\end{abstract}

Keywords-Housing prices; Macroeconomic; Factors; Review

\section{INTRODUCTION}

Since the 17 th century, about 21 of the 42 major global economic and financial crises have been linked to irrational changes in house prices. For example, the Japanese real estate bubble in the 1990s, the financial crisis in many southeast Asian countries, the subprime crisis in the 1920s and so on. Real estate prices are not only related to the ordinary people's daily life, but also related to the economic development and political changes of a city, more related to the state's economic stability, macro policies and so on. In China, the real estate industry, as a new industry that began to develop at the end of the $80 \mathrm{~s}$, is an important part of the development of China's national economy with the speed of its development, the breadth of the industry and the development of the economy. On the macro level, real estate is an important part of the economy and has an indispensable influence on the economy. At the micro level, real estate is an important part of family and enterprise assets. Here, because the macro-economy is an important way of the impact of house prices on the economic development, it is a comprehensive reflection of the choice of Chinese consumers and a benchmark for predicting the future trend of China's real estate. Therefore, we have studied the impact of house prices and macro economy.

\section{HOUSING PRICES AND MACROECONOMIC RESEARCH METHODS}

On the macro level, the important influence of real estate on economy is mainly reflected in its complex upstream and downstream relationship. Xu dianqing (2007) pointed out that the total value of American real estate in 2003 was 1.3 times of GDP1. On the one hand, macro-economy has an impact on the external living environment of the real estate market. On the other hand, changes in the assets of consumers or investors will also be affected by changes in the real estate price, which in turn will affect the macro economy by influencing consumption and investment. According to Quigley (2001), since the 1997 Southeast Asian financial Crisis broke out, how to promote the Real Estate market and the positive interaction of macroeconomic development become the focus of the attention from all walks of life 2 . The research methods of housing price and macroeconomics are mainly divided into traditional research methods and modern research methods.

\section{A. Traditional research methods}

- Based on the real estate supply and demand balance method. Many scholars at home and abroad from the perspective of supply and demand of housing prices, macroeconomic research (Muellbauer and Murphy (1997), Kenny (1999), hai-zhen wen, sheng-hua jia (2004), fu-quan xie, Huang Junhui (2013), HongShiQin (2007)). But this method of supply and demand balance to measure prices and macro economic relationship has much limitation in practical research in our country, because of physical and strict limitations of market in China, in which the government function is indispensable.

- The stock - flow model. Wheaton (1999) puts forward the stock - flow model, and takes the real estate market as a relatively independent market, and analyzes the influence of the macroeconomic factors as exogenous variables, such as population and labor, on the real estate market and house prices. However, the assumption that the model real estate market as a relatively exogenous market is unreasonable is lack of 
corresponding basis. Dan Mo (2010) [China's real estate cycle research based on the stock flow model, Renmin University of China.] analyses the important factors affecting the price and housing supply of China's commodity house by the stock flow model, it is found that many exogenous variables, such as land supply, population, income, policy and consumer expectations, have a significant impact on the change of house prices. The advantage of this method is that the study of house price formation mechanism is very clear, but the real real estate market can not exist as an independent market, so under this assumption, there may be some endogenous variables in some degree of external biochemistry.

- The price bubble model of rational expectation. This model divides house prices into two parts of basic value and bubble, the basic value part is the discount value for future earnings expectation, and the bubble satisfies a martingale process3.It is related to the expectations of the people. In the stage of irrational development of China's real estate market, this research method can reflect some practical problems to a certain extent. Yuan Zhigang and Fan Xiaoyan (2003) studied the existence and existence conditions of rational bubbles in housing prices by constructing a partial equilibrium model of the real estate market.

- A house price model based on asset pricing. It is divided into the asset pricing model based on the non arbitrage principle and the asset pricing model based on the consumption. The ratio of rent to house price ratio 4 refers to the ratio between the house price per square meter and the monthly rent per square meter, which roughly reflects the return on the investment obtained by the housing. It is derived from the principle of no arbitrage. But the special assets of real estate can not be measured solely by the income of ordinary assets. It has the advantages such as stability, value preservation, the advantages of the upstream and downstream industries, and the limitations of the extreme limited supply of land, such as government regulation and land supply, which restrict the authenticity of this hypothesis. Campbell et al. (2006) and Okumura (1997) respectively analyze the fluctuation of house prices in the United States and Japan based on second asset pricing models.

- The model of real estate price change and economic fluctuation under endogenous money supply. The model assumes that there are three interacting entities: the enterprise, the real estate market and the banks, and the enterprises are applying for real estate mortgage loans to the banks for investment. When housing prices rise, it will promote economic growth; when housing prices fall, investment and total output growth will shrink accordingly. Therefore, housing prices, money supply and total output are closely linked. Ding Chen and Tu Hongmei (2008) used this method to analyze the interaction between house price, currency and GDP.
- Financial acceleration model. Some very small external shocks in the economy can also cause large fluctuations in the economy (Bernanke, GertlerM, GilchristS (1999)). The financial acceleration mechanism, through the credit market, makes the value of real estate mortgage assets of consumers or investors closely related to macroeconomic changes. When the positive demand or policy impact in the economy increases the mortgage value of the real estate of the family or enterprise, the cost of financing and the scale of investment increase, which leads to a new round of rising house prices, thus making the economic change self strengthening.

\section{B. Modern research methods}

- VAR model. VAR model, as a powerful analysis method, can be used to analyze the impact of real estate development and macroeconomic variables. (Jiang Ying (2013), Lee (2007), Tu Jiahua (2005), Shen Yue (2006), Liu Hongyu and Zhang Hong (2006), Huang Zhong Hua et al (2008), Zhao Xindong (2010)). For example, Jiang Ying and Gao Yan Lin analyzed the relationship between the real estate industry and the growth of Guangdong's national economy in the framework of VAR model. The dynamic impact of demand impact, supply impact and monetary policy impact on China's real estate price changes and the dynamic impact of real estate price impact on GDP growth rate, inflation rate and the change of money stock growth rate are studied by Zhao Xindong's paper.

- The DSGE model.The dynamic stochastic general equilibrium model (DSGE) is the tool of the mainstream macro quantitative analysis. Compared with other macro economic research methods, the dynamic stochastic general equilibrium model has a microcosmic basis. The dynamic stochastic general equilibrium model has at least included the dynamic optimal row of many subjects such as consumers and vendors until the dynamic optimal line of the future indefinite period. We simulate the real economy by introducing different exogenous shocks. The DSGE model adds random shocks on the basis of dynamic general equilibrium model. Due to the random impact of economic operation, the equilibrium is random. When it is applied to the study of house price and macro economy, a new sector (Ma Yaming, Liu Cui (2014), Yi Bin (2015)) is added to the new real estate (or the consideration of land elements). For example, Ma Yaming, such as Ma Yaming, constructed a DSGE model containing multiple economic entities, one including real estate price fluctuations, the other not included, and the analysis of the two models of the simulation results to the real economy. Yi Bin built a new Keynes model considering the effect of credit friction and real estate mortgage guarantee, the model includes home, Court departments, intermediate manufacturers, retailers, real estate construction departments, and consider monetary policy and fiscal policy. 


\section{IMPACT OF HOUSING PRICES ON THE MACRO-ECONOMY}

The impact of housing price on macro-economy is mainly through interest rate, consumption and investment. There is no shortage of research literature on the relationship between house price and interest rate. Most studies of scholars show that housing price is negatively correlated with interest rate $(\mathrm{Yu}$ huayi, Chen dong (2009), Kau and Donald (1980), Harris (1989) and Cooper (2004))). For example, yu huayi and Chen dong believe that land price and interest rate are the key to the formation of house price. Land policy affects housing prices by influencing land prices. According to the data analysis, it is proved that there is a negative relationship between real interest rate and housing price in China. There is no unified conclusion about the interaction mechanism between housing price and consumption. Most scholars believe that the effect of housing price on consumption includes two channels. First, the direct channel, namely the wealth effect channel (Xie Jieyu et al. (2012), Huang Ping (2006), color, Zhu Guo Zhong (2013)). For example, Huang Ping (2006) found that there is a wealth effect in China's house price to a certain extent; secondly, the indirect channel is mainly the channel of credit effect, that is, the effect of house price change and real estate credit on consumption (Iacoviello (2004), Wang Ju, Guan Jinliang (2016)). Iacoviello, Wang Ju and Guan Jinliang believe that, based on the existence of the credit effect, when house prices rise, the mortgage value of real estate also rises, causing the increase of credit capacity, and eventually promoting the increase of consumption. The relationship between house price and investment is also concentrated on two kinds of effects: the first is the credit effect, that is, the price fluctuation will affect the balance sheet of the family and the enterprise, and then influence the scale of the credit, and ultimately affect the investment. When house prices fall, the net wealth of borrowers is reduced, resulting in reduced credit, which leads to reduced investment, which is the credit contraction mechanism; the second is the Tobin Q effect, the $\mathrm{Q}$ value indicates the ratio of house prices to real estate replacement costs, and the greater the $\mathrm{Q}$ value, the more profitable the real estate speculation is. At present, the research on this effect is mainly concentrated abroad, and there is still controversy about the existence of Tobin's Q effect.

The main factors that influence the real estate price are as follows: first, the influence of demand factors on the fluctuation of real estate price; Second, the supply factors on the real estate prices; Third, the impact of finance on the fluctuation of real estate prices; Fourth, the impact of macrocontrol on housing prices.

The early research mainly believed that the real estate price fluctuation's influence factor had two aspects: first, the economic level enhancement; two, the urban population growth The Chinese scholars generally agree that the real estate is short of elasticity in the short term, so the market demand is the main factor to determine the housing price (Downs, Nellis, Longbottom, Bartick, Jin Xiaobin (2015)). The influence of the supply factors on the price fluctuation of real estate is mainly concentrated on the supply of land. The land price is the most important factor in the supply cost. The influence of the land price on the house price has always been the hot spot of the research on the fluctuation of real estate price. On the one hand as the basic component of the cost of real estate products, land directly affects the house price; on the other hand, the land scarcity and fixed property lead to the incomplete competition of real estate products, which affects the house price (Gao Xiaohui (2001), Zhao Kecheng, Liu Weidong (2006), Gao Bo, Mao Feng (2003)). Many scholars believe that the change of land transfer mode promotes the rise of land price, but it is only the release of the low price of the market, and the land price is not the determinant of the formation of the price of the house. Gao Xiaohui explored the basic relationship between land price and housing price from the micro perspective of individual developers. Gao Bo, Mao Feng paid through the national data to study, found that in the short term, house prices and land prices mutual influence, and in the long term, the price trend determines the trend of land price. Zhao Kecheng and Liu Weidong believe that with the decline of land level, the impact of land prices on housing prices will gradually decrease. In our country, the characteristics of real estate determine that its development and sales are inseparable from the support of financial credit. Chai Qiang believes that rising interest rates have a great impact on housing prices. From a cost point of view, rising interest rates will increase investment interest in real estate development and increase housing prices; from a demand point of view, since the current purchase of housing is generally used for mortgage payments, interest rates are rising to reduce the effective demand for real estate and thus the price of housing is falling. In addition to the interest rate, Zhou Jingkui believes that the rise of housing prices is closely linked to loose monetary policy, and housing prices have greatly deviated from the long-term equilibrium value, and the market is irrational. Duan Zhongdong studied the causality between China's real estate prices and bank credit, and the results show that they are mutually causation.

In China, a market economy country with Chinese characteristics, the role of the government can not be ignored. In addition to the influence of supply, demand and finance, the real estate price has become another important factor affecting the real estate price (Xiao Yuanzhen, Jiang De Jun (2006), Liao Junping (2006), Liang (2006)). Yun Fang, Gao Tiemei (2007)). Xiao Yuanzhen, Jiang Dejun, etc. introduced the real estate development of Japan, the United States, Russia and Singapore, and the government's regulation on the rise of house prices, which provided some reference and experiment for the real estate regulation and control in China. Liao Junping believes that macroeconomic regulation and control should focus on the implementation and implementation of policies, and strengthen supervision and management of the implementation of existing policies. Liang Yunfang and Gao Tiemei analyzed the reasons for the difference of house price fluctuations in different regions. The study found that there are obvious regional differences in the effect of real estate regulation policies. 


\section{CONCLUSION}

Through the analysis of the relationship between housing prices and macroeconomic, we know that the two are interrelated. Many factors in the macro-economy will affect the fluctuation of real estate prices. A series of potential factors, such as consumer population, production cost, inflation and economic forecast, will cause the adjustment of house prices and the change of real estate structure. Similarly, the changes in real estate prices will also affect the development of macroeconomic, credit, $\mathrm{Q}$ value, the flow of real estate as well as the existing and future wealth effect will lead to the reduction or increase of investment, which will affect social production and output, and affect the living standard and consumption level of the residents. Therefore, it is very important to correctly grasp the relationship between real estate price and macro economy. On the one hand, we should make housing price and macro economy promote each other and develop together in the direction of health and stability. On the other hand, we should ensure the healthy development of the connection between house price and macro economy, avoid the excessive rise of house prices or the disagreement of macro economy which would lead to severe social contradictions and problems.

The contradiction in the real estate industry is a concentrated reflection of various contradictions in the process of China's economic transformation. It can be said that in the current development stage, the real estate market in China has fully met the importance of the system, and the historical experience has repeatedly proved that if the economic and financial development is too heavy on real estate and the price of real estate continues to rise, it is very likely to become a structural short board to touch the systemic risk. And it will cause great harm to the sustained, stable and healthy development of the national economy. So we hope to study the existed research to find a better way to stop the threatens that real estate caused to us. The research on the factors influencing housing price in foreign countries is earlier than that in China, and much attention is paid to quantitative research and case study, which provide a good reference for domestic research. The relevant research on real estate prices in China is also gradually improved. The particularity of China's national conditions and status determines that there is still more deep research space in this area.

\section{REFERENCES}

[1] QuigleyJ M. Real Estate and the Asian Crisis [J].Journal of Housing Economics, 2001, 10 (2):129 - 161.

[2] KennyG. Modelling the demand and supply sides of the housing market: evidence from Ireland [J]. Economic Modelling, 1999, 16(3):389 - 409.

[3] Lee C I. Does Provision of Public Rental Housing Crowd out Private Housing Investment? A Panel VAR Approach [J]. Journal of Housing Economics, 2007, 16(1):1 - 20.

[4] Okumura T. Housing Investment and Residential Land Supply in Japan: An Asset Market Approach [J]. Journal of the Japanese and International Economies, 1997, 11(1):27 - 54

[5] CampbellS D, DavisM A, Gallin J, et al. A Trend and Variance Decomposition of the Rent-Price Ratio in Housing Markets [EB/OL], 2006-09-16.

[6] BernankeB, GertlerM, GilchristS. The Financial Accelerator in a Quantitative Business Cycle Framework [A]. // In Taylor J, Woodford M (Eds).Handbook of Macroeconomics [M]. Amsterdam: Elsevier Science, 1999:1341 - 1391.

[7] Kau J B, Donald C K.1980, the Theory of Housing and Interest Rates [J]. Journal of Financial and Quantitative Analysis, 15(4):833 - 847.

[8] Harris J C. 1989, the Effect of Real Rates of Interest on Housing Prices [J]. Journal of Real Estate Finance and Economics, 2(1):47 - 60.

[9] Cooper A. 2004, The Impact of Interest Rates and the Housing Market on the UK Economy [J]. Economic Outlook, 28(2): 10 - 18.

[10] Iacoviello M. Consumption, House Prices, and Collateral Constraints: A Structural Econometric Analysis [J]. Journal of Housing Economics, 2004, 13 (4):304 - 320. 